American Journal of Environmental Sciences 1 (3): 206-208, 2005

ISSN 1553-345X

(c) 2005 Science Publications

\title{
Electro-diagnostic and Clinical Changes of Peripheral Neuropathies in Bam Earthquake Victims
}

\author{
${ }^{1,2}$ Naser Zangiabadi and ${ }^{3}$ Mohammad Naeem Ahrari \\ ${ }^{1}$ Afzal Research Institute, Shahid Rajaee Street, Kerman, Iran \\ ${ }^{2}$ Kerman Neuroscience Research Center, Kerman Medical Sciences University, Kerman, Iran \\ ${ }^{3}$ Department of Physical Therapy and Rehabilitation, Kerman Medical Sciences University, Kerman, Iran
}

\begin{abstract}
To examine and diagnose patients who injured in Bam earthquake at 5:26:52 Am (local time) on Friday, December 26, 2003 with traumatic peripheral neuropathies then treat and follow up. A longitudinal study was deigned. 159 patients with traumatic neuropathies were selected at the first stage of study. After six months follow up only 39 patients satisfied to enter the study. Clinical examination, Nerve conduction velocity, $\mathrm{F}$ wave and $\mathrm{H}$ wave were done and registered. The male and female frequency was equal (19M/20F) and average of age was 31.1+/-11.6. During 6 months period following earthquake 19 cases $(48.7 \%)$ were improved in healing of neuropathies and were better in both neurological examination and electro-diagnostic tests. The repeated measurement analysis of variances did not reveal any difference in healing of nerves in sex and age groups. So patients' gender and age did not influence on recovery of neuropathies. The neuropathy injuries in Bam earthquake was the same as other earthquakes in Japan, China and Turkey, approximately. The notification to neuropathy in crush injuries and extremity damage for early diagnosis and treatment of neuropathies is considerable. At the earthquake disaster management, It is important that trained person rescue the victims to prevent extra injuries.
\end{abstract}

Key words: Iran, neuropathy, earthquake, electro-diagnostic, bam

\section{INTRODUCTION}

A severe earthquake struck the ancient city of Bam in Kerman province, southeast Iran at 5:26:52 Am (local time) on Friday, December 26, 2003. The magnitude of the earthquake was 7.2 on the Richter scale $^{[1]}$.

The UN office for the Coordination of Humanitarian Affairs (OCHA) indicates that Bam earthquake caused the deaths of approximately 43200 residents and injured approximately $20000^{[1,2]}$.

The type and severity of injuries depended on the time of earthquake occur. Because the Bam earthquake happened early in the morning when most people were still in bed, many people were entered under the derbies of their bricky house. Bone fracture, head injury, crush syndrome and traumatic neuropathies were the major injuries encountered.

In Tangshan earthquake in China-1976 and Hanshin-Awaji earthquake in Japan-1995 the major injuries were crush syndrome, pelvic fracture and traumatic paralegia ${ }^{[3,4]}$.

After Bam earthquake we examined and diagnosed 159 patients who injured in earthquake with traumatic peripheral neuropathies then treated and followed up. So we decided revealed recovery after 6 month. This study try to describe the prognosis and electro- diagnostic finding of peripheral nerve palsy of victims in Bam earthquake.

\section{MATERIALS AND METHODS}

At the first stage of study, 159 patients who had been injured in Bam earthquake and complained to any symptoms regarding to neuropathy visited by neurologist and referred for electro-diagnostic test at least 3 weeks after earthquake. They were 82 male and 77 female with average age 29.6+/-13 (mean+/-SD). Totally 383 nerves were involved. 203 nerves in lower extremity and 173 in upper extremity and 7 cases had facial neuropathy.

All patients were treated conservatively and followed up 6 months. After 6 months all patients were invited to neurology clinic but only 39 patients cooperated and agreed to take part in the second stage of study.

For the purpose of this study, patients were examined by neurologist and then referred to physical therapist for electro-diagnostic tests (EDT). EDT was contained EMG and NCV which done by one specialist by Toenis-Germany Electro-diagnostic system. Nerve conduction velocity, $\mathrm{F}$ wave and $\mathrm{H}$ wave were registered. The information including sex, age, specific nerve injury, side of injury and EDT were collected and

Corresponding Author: Naser Zangiabadi (MD), Neuroogist, Afzal Research Institute,

Samen-el Hodjaj Special Disease Center, Shahid Rajaee Street, Kerman, Iran, Tel: +989131404389 
entered into a spreadsheet for each patient/nerve injury.

The collected data were assessed using SPSS-11.5 software by PC. Paired t test compared the mean of EDT parameters between 2 stages of study. The mean differences of these parameters were adjusted between sex and age groups by repeated measurement of ANOVA. An alpha level of $\mathrm{p}<0.05$ was used for all analysis.

\section{RESULTS}

Of the 39 patients who were evaluated in second stage, 6 months after Bam earthquake. The male and female frequency was equal $(19 \mathrm{M} / 20 \mathrm{~F})$. They were young predominantly which mean of age was $31.1+/$ 11.6. The 18 cases had upper extremity and 21 had lower extremity neuropathy. (Fig. 1). During 6 months period following earthquake 19 cases $(48.7 \%)$ were improved in healing of neuropathies and were better in both neurological examination and EDTs. The mean of electro-diagnostic parameters were better in the second stage and the means difference were significant (Table1). The best recovery had been regarding to median and peroneal nerves (Table-2).

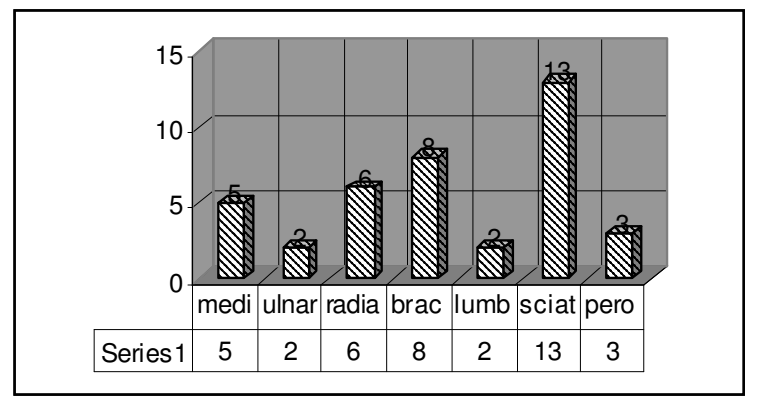

Fig. 1: Distribution of involved nerve

Table 1: The mean of EDT parameter in two stage of study

\begin{tabular}{lllll}
\hline Statistics Parametrs & Mead & SD & Paired t test \\
\hline $1^{\text {st }}$ & $\mathrm{NCV}, 2^{\text {nd }} \mathrm{NCV}$ & $15.4,22.5$ & $2.8,3.6$ & $\mathrm{P}<0.0001$ \\
$1^{\text {st }}$ & $\mathrm{F}$ wave, $2^{\text {nd }} \mathrm{F}$ wave & $1.3,13.2$ & $1.8,3.2$ & $\mathrm{P}<0.0001$ \\
$1^{\text {st }}$ & $\mathrm{H}$ wave, $2^{\text {nd }} \mathrm{H}$ wave & $0.8,4.2$ & $0.8,1.7$ & $\mathrm{P}=0.032$ \\
\hline
\end{tabular}

Table 2: Recovery of nerve after six months

\begin{tabular}{lccc}
\hline Recovery Nerve & Yes & No & Total \\
\hline Median & 5 & 0 & 5 \\
Ulna & 1 & 1 & 2 \\
Radial & 3 & 3 & 6 \\
Brachial plexus & 2 & 6 & 8 \\
Lumbosacral & 0 & 2 & 2 \\
Sciatic & 6 & 7 & 13 \\
Peroneal & 3 & 0 & 3 \\
Total & 20 & 19 & 39 \\
\hline
\end{tabular}

The repeated measurement analysis of variances did not reveal any difference in healing of nerves in sex and age groups. So patients' gender and age did not influence on recovery of neuropathies.

\section{DISCUSSION}

Extremity traumas are the most common type of injury in the earthquakes ${ }^{[5-7]}$. Subsequently, peripheral neuropathies occur. The literature is consistent in reporting the higher incidence of peripheral nerve injuries in upper extremity with the lower extremity ${ }^{[8-9]}$. I our study upper extremity nerve injury was higher than lower. In Hanshin-Awaji earthquake were the same as ourselves ${ }^{[10]}$. However Sarisozen and Durak reported the higher incidence of neuropathy in lower extremity from Marmara earthquake. Of course they had evaluated children ${ }^{[11]}$.

Sciatic nerve palsy was the most frequent neuropathy. It seems that it was in order to crush syndrome because of burying of people under the debris of their houses. In upper extremity brachial plexus palsy was the most. We thought that it was resulting to push the injured under debris and stretch injuries were occurred. Recovery from median and peroneal nerves was complete and the ulna, radial and sciatic was in average but in brachial and lumbosacral plexus were poor. None of patients with lumbosacral plexus injury were recovered and only one with brachial plexus neuropathy was good recovery. Uzun and coworkers reported recovery the same as our study ${ }^{[12]}$. Whereas it was in contrast to Japanese study, they demonstrated recovery from brachial plexus injuries generally were good and recovery of the radial, ulna and median nerve palsy group was poor. Recovery from palsies was good in the lower extremity ${ }^{[10]}$.

The difference between Iran and Turkey earthquake to Hanshin-Awaji in Japan is to the material of building houses.

Finally, two mechanisms of injury result in peripheral neuropathy, one is a long period of comparison that caused crush syndrome and was unavoidable. The other which preventable was an acute force on the nerve during stretching extremities for rescuing. It is important that trained person rescue the victims to prevent extra injuries.

The other point is exact neurology examination will save injured from paralysis following traumatic neuropathy.

\section{AKNOWLEDGMENT}

This study was supported by Kerman Neuroscience Research Center that arise our thanks, furthermore we appreciate to Dr Hossein Eskandari, professor of neurosurgery in Kerman medical school for his exact note, and Dr Mohammad-Arash Ramezani for data analysis and editing this paper, and Mehrak Memaran Dadgar for grateful guides. 


\section{REFERENCES}

1. Learning from earthquake. 2003. Preliminary observations on the Bam, Iran earthquake of December 26. 2003. Available in: www.abscosulting.com/news/LFETEAMS.df

2. WHO joints international effort to help Bam earthquake survivors? Bulletin of WHO. 2004, February; 24: 156

3. Shing, Z.Y., 1987. Medical support in the Tangshan earthquake: A review of the management of mass causalities and certain major injuries. J. Trauma. 27: 1130-35.

4. Oda, J., H. Tanaka, T. Yoshida, ad et al., 1997. Analysis of 3732 patients with crush syndrome caused by the Hanshin-Awaji earthquake. J. Trauma;42:470-76

5. Armenian, H.K., A. Melkonian, E.K. Noji and A.P. Hovanesian, 1997. Deaths and injuries due to the earthquake in Armenia: A cohort approach. Int. J. Epidemiol.;26:806-15.

6. Kuwagata, Y., J. Oda, H. Tanaka and et al, 1997. Analysis of 2702 traumatized patients in the 1995 Hanshin-Awaji earthquake. J. Trauma;43:427-32.
7. Peek-Asa, C., J.F. Kraus, L.B. Bourque and et al, 1998. Fatal and hospitalized injuries resulting from the 1994 Northridge earthquake. Int. J. Epidemiol.;27: 459-65.

8. Baber, S., 1993. Peripheral nerve injuries in third word country. Cent. Afr. J. Med.;39:120-25.

9. Noble, J., C. Munro, V.Parsad and R. Midha, 1998. Analysis of upper and lower peripheral nerves injuries in population of patients with multiple traumas. J. Trauma.;45:116-22.

10. Yoshida, T., K. Tada, K. Uemura and K. Yonenbu, 1999. Peripheral nerve palsies in the victims of Hanshin-Awaji earthquake. Clin. Orthop.;362:20817.

11. Sarisozen, B. and K. Durak, 2003. Extremities injuries in children resulting from the Marmara earthquake. J. Pediatr. Orthop.;12:288-91.

12. Uzan, N., F.K. Saukun, S. Yazisi and et al, 2001. Experiences obtained in electromyography laboratory after the August 1999 earthquake. Cerrahpasa. J. Med.;32: 169-72. 